\title{
Asymmetric Polymerization of 1-(3-Pyridyl)dibenzosuberyl Methacrylate and Chiral Recognition by the Obtained Optically Active Polymer Having Single-Handed Helical Conformation
}

\author{
Tamaki Nakano, Yoichi Satoh, and Yoshio Okamoto \\ Department of Applied Chemistry, Graduate School of Engineering, Nagoya University, \\ Chikusa-ku, Nagoya 464-8603, Japan
}

(Received December 10, 1997)

\begin{abstract}
Pyridyl)dibenzosuberyl methacrylate was synthesized and polymerized using the complexes of $N, N^{\prime}$-diphenylethylenediamine monolithium amide with (+)-1-(2-pyrrolidinylmethyl)pyrrolidine, (+)-2,3-dimethoxy-1,4bis(dimethylamino)butane, and (-)-sparteine in toluene at $-78^{\circ} \mathrm{C}$. The polymers obtained by the helix-sense-selective anionic polymerization were highly isotactic and exhibited large dextrorotation based on single-handed helical conformation. Free-radical polymerization in toluene with (iso-PrOCOO) ${ }_{2}$ at $40^{\circ} \mathrm{C}$ and with $\alpha, \alpha^{\prime}$-azobisisobutyronitrile at $60^{\circ} \mathrm{C}$ gave nearly perfectly isotactic polymers. The optically active polymer exhibited chiral recognition ability toward trans-stilbene oxide and Tröger's base as revealed by chiral adsorption experiments.
\end{abstract}

KEY WORDS 1-(3-Pyridyl)dibenzosuberyl Methacrylate / Triphenylmethyl Methacrylate / 1-Phenyldibenzosuberyl Methacrylate / Helix / Anionic Polymerization / Free-Radical Polymerization / Chiral Recognition /

Several bulky methacrylates with triarymethyl ester groups including triphenylmethyl ${ }^{1,2}$ and diphenyl-2-pyridylmethyl $^{3,4}$ esters (TrMA and D2PyMA) are known to give single-handed helical, optically active polymers with highly isotactic main-chain configuration by asymmetric anionic polymerization (helix-sense-selective polymerization). The optically active polymers are valuable as chiral stationary phases for high-performance liquid chromatography (HPLC) and some of them are already commercialized. ${ }^{6}$ Among the bulky methacrylates, 1phenyldibenzosuberyl and 1-(2-pyridyl)dibenzosuberyl methacrylates (PDBSMA and 2PyDBSMA) having 1aryldibenzosuberyl backbone in ester group are especially intriguing because they exhibit higher durability against solvolysis and higher isotactic specificity even in free-radical polymerization compared with TrMA and D2PyMA, respectively, which are their analogues having a diphenylmethyl group instead of a dibenzosuberyl group. ${ }^{7-10}$ Higher durability against solvolysis is an important property of a monomer because the solvolysis of ester linkages in the helical polymethacrylates leads to a loss of the helical conformation and chiral recognition ability.

In this work, we synthesized 1-(3-pyridyl)dibenzosu-
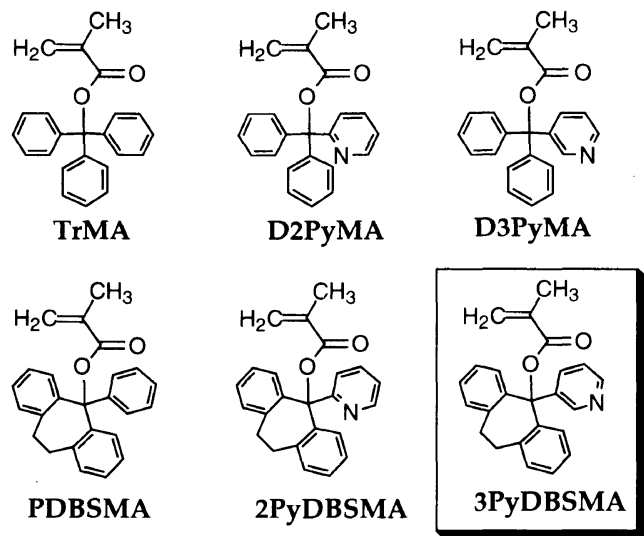

beryl methacrylate (3PyDBSMA), a new monomer containing 1-aryldibenzosubery moiety, and examined its durability against solvolysis and polymerization behavior in asymmetric anionic and free-radical catalyses. Diphenyl-3-pyridylmethyl methacrylate (D3PyMA), the parent monomer of 3PyDBSMA with the triarymethyltype side group, has been synthesized and its properties and polymerization behavior have already been reported. ${ }^{11}$

\section{EXPERIMENTAL}

\section{Materials}

3-Bromopyridine (Tokyo Chemical Industry) was dried on $\mathrm{CaH}_{2}$ and distilled under reduced pressure immediately before use. Dibenzosuberone (Aldrich) was used as obtained. Ether and tetrahydrofuran (THF) were distilled over $\mathrm{Na}$ wire and stored under nitrogen in the dark. Purification of the other materials including those for anionic polymerization has been shown in the literature. $^{2}$

\section{Synthesis of $3 P y D B S M A$}

3PyDBSMA was prepared by the method applied for the synthesis of 2PyDBSMA ${ }^{8}$ with modifications. 3Bromopyridine $(30 \mathrm{~g}, 0.190 \mathrm{~mol})$ was added dropwise to a solution of butyllithium $(0.198 \mathrm{~mol})$ in $250 \mathrm{ml}$ of ether cooled at $-78^{\circ} \mathrm{C}$ with stirring under dry nitrogen atmosphere and the reaction mixture was allowed to stand for $90 \mathrm{~min}$ with stirring to form a 3-lithiopyridine solution. A solution of benzophenone $(34.7 \mathrm{~g}, 0.167 \mathrm{~mol})$ in $76 \mathrm{ml}$ of dry ether was added with vigorous stirring and the reaction was quenched by adding aq $\mathrm{NH}_{4} \mathrm{Cl}$ after stirring at $-50^{\circ} \mathrm{C}$ for $4 \mathrm{~h}$. The products were extracted using $\mathrm{CHCl}_{3}$ and recrystallized from a mixture of benzene and hexane $(9: 1, \mathrm{v} / \mathrm{v})$ to yield pure colorless crystals of 1-(3-pyridyl)dibenzosuberol. Yield $42.0 \mathrm{~g}$ (87.5\%). mp $151.2-151.9^{\circ} \mathrm{C} .{ }^{1} \mathrm{H}$ NMR $\left(500 \mathrm{MHz}, \mathrm{CDCl}_{3}, \mathrm{Me}_{4} \mathrm{Si}\right)$ $\delta 7.07-8.35(\mathrm{~m}, 12 \mathrm{H}$, aromatic $\mathrm{H}), 3.60(\mathrm{~s}, 1 \mathrm{H},-\mathrm{OH})$, 


\section{$2.70-2.86\left(\mathrm{~m}, 4 \mathrm{H},-\mathrm{CH}_{2} \mathrm{CH}_{2}-\right)$.}

In a $1-\mathrm{L}$ flask equipped with a dropping funnel was placed KH (dispersion in mineral oil, $35 \mathrm{wt} \%)(25.6$ g, $0.224 \mathrm{~mol})$. THF $(100 \mathrm{ml})$ was introduced with a syringe and the mixture was stirred to remove oil from $\mathrm{KH}$. After stirring was stopped, the supernatant THF wash was removed with a syringe. Fresh THF $(90 \mathrm{ml})$ was added to the washed $\mathrm{KH}$ and 1-(3-pyridyl)dibenzosuberol $(20 \mathrm{~g}, 0.070 \mathrm{~mol})$ dissolved in $180 \mathrm{ml}$ of THF was added dropwise in a $2-\mathrm{h}$ period with stirring at room temperature. After completion of $\mathrm{H}_{2}$ generation, methacryloyl chloride $(10.2 \mathrm{ml}, 0.104 \mathrm{~mol})$ was added dropwise to the mixture cooled at $0^{\circ} \mathrm{C}$. After stirring for $1 \mathrm{~h}$ at $0^{\circ} \mathrm{C}$, the reaction mixture was decomposed by carefully adding water. The products were extracted using THF and recrystallized from a mixture of ether and hexane $(1: 1, \mathrm{v} / \mathrm{v})$ to yield pure colorless crystals of 3PyDBSMA. Yield $12.0 \mathrm{~g}(49.0 \%) \mathrm{mp}$ $113.8-114.8^{\circ} \mathrm{C} .{ }^{1} \mathrm{H}$ NMR $\left(500 \mathrm{MHz}, \mathrm{CDCl}_{3}, \mathrm{Me}_{4} \mathrm{Si}\right)$ $\delta 7.10-8.68(\mathrm{~m}, 12 \mathrm{H}$, aromatic $\mathrm{H}), 5.67$ and $6.28(\mathrm{~m}$, $2 \mathrm{H}$, vinyl $\mathrm{H}$ ), $3.13-3.22\left(\mathrm{~m}, 4 \mathrm{H},-\mathrm{CH}_{2} \mathrm{CH}_{2}-\right), 1.98(\mathrm{~s}, 3 \mathrm{H}$, $\left.\alpha-\mathrm{CH}_{3}\right)$. IR $(\mathrm{KBr}) 1636 \mathrm{~cm}^{-1}(\mathrm{C}=\mathrm{C}), 1725 \mathrm{~cm}^{-1}(\mathrm{C}=$ O). Anal. Calcd for $\mathrm{C}_{24} \mathrm{H}_{21} \mathrm{O}_{2} \mathrm{~N}$ : C, $81.10 \% ; \mathrm{H}, 5.96 \%$; N, 3.94\%. Found: C, $81.11 \%$; H, 6.04\%; N, 3.61\%.

\section{Methanolysis of $3 P y D B S M A$}

Methanolysis reaction was carried out in a mixture of $\mathrm{CD}_{3} \mathrm{OD}$ and $\mathrm{CDCl}_{3}(1: 1, \mathrm{v} / \mathrm{v})$ at $35^{\circ} \mathrm{C}$ using an NMR sample tube $(5 \mathrm{~mm} \phi)$ (Wilmad 507-PP)) as a reaction vessel and the reaction was monitored directly by means of ${ }^{1} \mathrm{H}$ NMR spectroscopy. 3PyDBSMA $(0.133 \mathrm{~g}, 0.374 \mathrm{mmol})$ was dissolved in $\mathrm{CDCl}_{3}(0.4 \mathrm{ml})$ and the solution was kept at $35^{\circ} \mathrm{C}$ using a water bath. Immediately after $\mathrm{CD}_{3} \mathrm{OD}(0.4 \mathrm{ml})$ was added to the solution and the mixture was homogenized, the sample tube was set into the NMR system whose probe temperature was adjusted to $35^{\circ} \mathrm{C}$ and the measurement was started. Interval time between measurements varied from $20 \mathrm{~min}$ (initial stages) to $6 \mathrm{~h}$ (final stages). Using $45^{\circ}$ pulse, sixteen free induction decays (FIDs) were accumulated for a set of measurement which took $1.3 \mathrm{~min}$. The obtained data gave a good first-order plot (not shown). The rate constant of methanolysis $(k)$ was calculated from the slope of the plot and the half-life period was obtained from $k$.

\section{Polymerization}

The method of polymerization is the same as that reported for $\operatorname{TrMA}^{2}$ except that $N, N^{\prime}$-diphenylethylenediamine monolithium amide (DPEDA-Li) was used as an initiator instead of 9-fluorenyllithium. See Table II for more details of the reaction conditions. Part of the obtained polymer was converted to methyl ester (poly(methyl methacrylate) (PMMA)) by solvolysis of the ester group using $\mathrm{MeOH}$ containing $\mathrm{HCl}$ followed by methylation using $\mathrm{CH}_{2} \mathrm{~N}_{2}$. Tacticity of the polymers was determined by ${ }^{1} \mathrm{H}$ NMR analysis $\left(\mathrm{CDCl}_{3}, 60^{\circ} \mathrm{C}\right)$ of PMMA derived from the original polymer. The degree of polymerization (DP) and molecular weight distribution of the polymers were determined by GPC of the PMMA using a polystyrene calibration curve.

\section{Chiral Absorption}

Finely ground poly(3PyDBSMA) (20 mg) was placed in a 2-ml screw-capped glass vial. A hexane-2-propanol mixture $(95: 5, \mathrm{v} / \mathrm{v})(1 \mathrm{ml})$ was added to wash the polymer prior to the chiral absorption experiment and the supernatant wash solution was removed with a syringe after standing at room temperature $\left(\mathrm{ca} .25^{\circ} \mathrm{C}\right)$ for $30 \mathrm{~min}$. After the washing process was repeated three times, the polymer was dried under reduced pressure. A solution of racemic compound in a hexane-2-propanol mixture $\left(100 \mu \mathrm{l}\right.$, conc. $\left.=0.5 \mathrm{gl}^{-1}\right)$ was added to the polymer and the mixture was permitted to stand for $3 \mathrm{~h}$ with the vial tightly capped. An aliquot $(10 \mu \mathrm{l})$ of the supernatant solution was then sampled with a micro syringe and analyzed using a chiral HPLC system with a Daicel Chiralcel OD column $(25 \mathrm{~cm} \times 0.46 \mathrm{~cm}$ (i.d.)) equipped with UV and polarimetric detectors to determine the concentration and e.e. of analyte in the sample solution.

Separation factor $\left(\alpha_{1}\right.$ and $\left.\alpha_{2}\right)$ was calculated by two methods. $\alpha_{1}$ was obtained according to the following equation where the superscripts ' $f$ ' and 'abs' mean free (in solution part) and absorbed (on the polymer), respectively:

$$
\begin{aligned}
& \text { (major antipode } \left.{ }^{\mathrm{f}}(\%)\right) /(\text { minor antipode } \mathrm{f}(\%))
\end{aligned}
$$

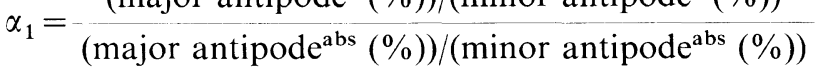

$$
\begin{aligned}
& \text { (major antipode } \left.\mathrm{f}^{\mathrm{f}}(\%)\right) /\left(\text { minor antipode }{ }^{\mathrm{f}}(\%)\right) \\
& \left(50-\text { major antipode }{ }^{\mathrm{f}}(\%)\right) /\left(50-\text { minor antipode }{ }^{\mathrm{f}}(\%)\right)
\end{aligned}
$$

where

$$
\begin{aligned}
& \text { major antipode }^{\mathrm{f}}(\%)=(100-\text { adsorption yield }(\%)) \\
& \times\left(100+\mid \text { e.e. } .^{\mathrm{f}} \mid\right) / 2 \times 1 / 100 \\
& \text { minor antipode }^{\mathrm{f}}(\%)=(100-\text { adsorption yield }(\%)) \\
& \times\left(100-\mid \text { e.e. }{ }^{\mathrm{f}} \mid\right) / 2 \times 1 / 100
\end{aligned}
$$

$\alpha_{2}$ was calculated according to the following equation:

$$
\alpha_{2}=\left(\text { major antipode }{ }^{\mathrm{f}}(\%)\right) /\left(\operatorname{minor} \operatorname{antipode}^{\mathrm{f}}(\%)\right)
$$

\section{Measurement}

${ }^{1} \mathrm{H}$ NMR spectra were taken on a Varian VXR-500 spectrometer $\left(500 \mathrm{MHz}\right.$ for ${ }^{1} \mathrm{H}$ measurement) or a Gemini 2000 spectrometer $\left(400 \mathrm{MHz}\right.$ for ${ }^{1} \mathrm{H}$ measurement). IR spectra were taken on a JASCO FT/IR-7000 spectrometer. Optical rotation was measured with a JASCO DIP-181 polarimeter using a $0.5-\mathrm{dm}$ quartz cell. Circular dichroism (CD) spectra were taken using a JASCO J-720L spectrometer. GPC of poly(3PyDBSMA) was performed with a Shodex System-21 GPC system equipped with a Shodex UV-41 detector and a JASCO OR-990 polarimetric $\left(\alpha_{\mathrm{Hg}}\right)$ detector using Shodex KF803 and KF-806F GPC columns connected in series (eluent, THF; flow rate, $1.0 \mathrm{ml} \mathrm{min}^{-1}$; temp, $40^{\circ} \mathrm{C}$ ). A Shodex RI-71S detector was used in place of a Shodex UV-41 detector for the GPC analysis of PMMA.

\section{RESULTS AND DISCUSSION}

\section{Durability of Monomer}

Prior to the polymerization study, the durability of the monomer against methanolysis was examined by 
measuring the rate of the reaction in Scheme 1 by means of ${ }^{1} \mathrm{H}$ NMR spectroscopy.

The results are shown in Table I along with those for other monomers. ${ }^{8,11,12}$ 3PyDBSMA was more durable compared with PDBSMA probably because of the electron withdrawing effect of the 3-pyridyl group which destabilizes 1-aryldibenzosuberyl cation which is an intermediate of the solvolysis reaction. However, 3 PyDBSMA was more readily solvolyzed than 2 PyDBSMA. The electron-withdrawing effect of $\mathrm{N}$ atom in pyridyl ring may be slightly greater when it is at 2-position than at 3-position.

A notable feature in the present results is that 3PyDBSMA is less durable than D3PyMA, which is not consistent with our previous conclusions derived from the comparison of TrMA with PDBSMA and that of D2PyMA with 2PyDBSMA that introducing a dibenzosuberyl structure in place of a diphenylmethyl group in the side chain increases the durability of ester linkage. The results obtained in this work suggest that the stability of the intermediate tertiary cation is not the only factor that affects the durability of ester linkage.

Methanolysis reaction process is considered to involve the interaction of carbonyl oxygen and acidic methanolic hydrogen since methanolysis of bulky methacrylates is

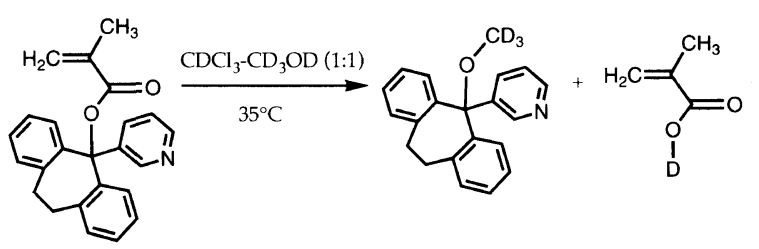

Scheme 1. Methanolysis of 3PyDBSMA.

Table I. Methanolysis of methacrylates ${ }^{\mathrm{a}}$

\begin{tabular}{cccc}
\hline & & \multicolumn{1}{c}{$k$} & \multicolumn{1}{c}{ Half-life period } \\
\cline { 3 - 3 } Run & Monomer & $\mathrm{h}^{-1}$ & $\min$ \\
\hline $1^{\mathrm{b}}$ & TrMA & 2.86 & 14.5 \\
$2^{\mathrm{c}}$ & PDBSMA & 0.466 & 89.0 \\
$3^{\mathrm{b}}$ & D2PyMA & 0.0256 & 1620 \\
$4^{\mathrm{c}}$ & 2PyDBSMA & 0.0165 & 2520 \\
$5^{\mathrm{d}}$ & D3PyMA & 0.0291 & 1439 \\
$6^{2}$ & 3PyDBSMA & 0.0444 & 936
\end{tabular}

${ }^{a}$ See EXPERIMENTAL for detailed conditions. ${ }^{b}$ Data were cited from ref $12 .{ }^{\mathrm{c}}$ Data were cited from ref $8 .{ }^{\mathrm{d}}$ Data were cited from ref 11 . known to be accelerated by protonic acid such as $\mathrm{HCl}$. Probably, the 3-pyridyl nitrogen in D3PyMA can interact with $\mathrm{MeOH}$ molecules through hydrogen bonding more readily compared with that in 3PyDBSMA because of less steric hindrance to more efficiently prevent methanol molecules from approaching carbonyl oxygen.

\section{Asymmetric Anionic Polymerization and Free-Radical Polymerization}

Asymmetric anionic polymerization was carried out in toluene at $-78^{\circ} \mathrm{C}$. The complexes of $N, N^{\prime}$-diphenylethylenediamine monolithium amide (DPEDA-Li) with (+)-1-(2-pyrrolidinylmethyl)pyrrolidine (PMP), (+)2,3-dimethoxy-1,4-bis(dimethylamino)butane (DDB), and $(-)$-sparteine $(\mathrm{Sp})$ were used as anionic initiators. These initiators are known to lead PDBSMA to singlehanded helical polymers. ${ }^{8}$ The results of anionic polymerization are shown in Table II (runs $1-3$ ). The obtained poly(3PyDBSMA)s had highly isotactic configuration as revealed by ${ }^{1} \mathrm{H}$ NMR spectra of PMMA derived from the original polymers and exhibited high specific rotation, suggesting that the polymers have helical conformation with excess helicity. The specific rotation values of the polymers obtained with the PMP and DDB complexes were comparable to those of singlehanded helical poly(PDBSMA) and poly(2PyDBSMA). ${ }^{11}$ In addition, the polymer of run 3 in Table II showed intense $C D$ absorbance bands $\left([\theta]_{237 \mathrm{~nm}} 96000 \mathrm{deg} \mathrm{m}^{2}\right.$ $\mathrm{mol}^{-1},[\theta]_{269 \mathrm{~nm}} 19000 \mathrm{deg} \mathrm{m}^{2} \mathrm{~mol}^{-1}$ (in THF)) whose magnitude is similar to that of single-handed helical poly(PDBSMA). These results indicate that the polymers synthesized with PMP and DDB possess singlehanded helical structure.

The anionic polymerization behavior of 3PyDBSMA is quite different from that of 2PyDBSMA where $\mathrm{Sp}$ and PMP gave single-handed helical polymer and DDB gave only oligomers. The difference is assumed to be based on different coordination chemistries involving

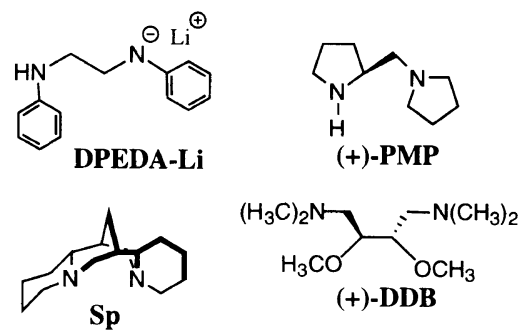

Table II. Polymerization of 3PyDBSMA ${ }^{\mathrm{a}}$

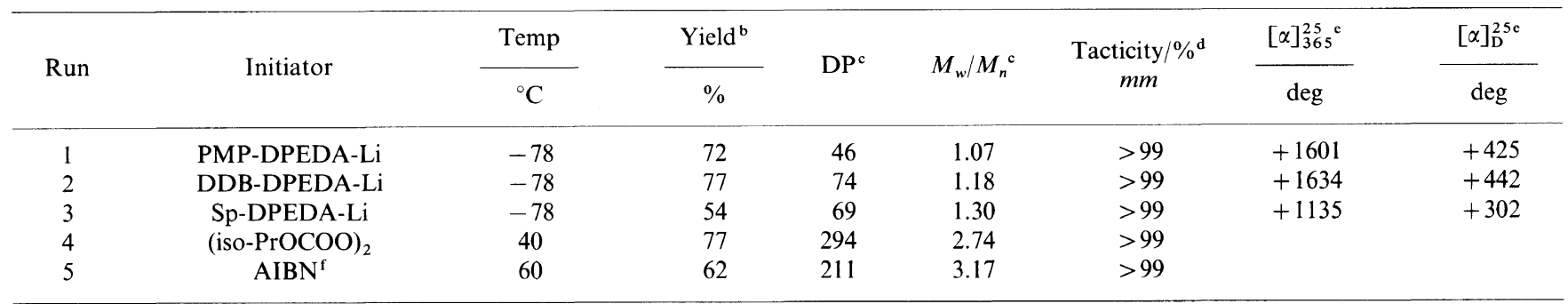

${ }^{a}$ Monomer $1.0 \mathrm{~g}$, toluene $20 \mathrm{ml}$, [monomer]/[initiator] $=20$ (run 1); monomer $0.5 \mathrm{~g}$, toluene $1.0 \mathrm{ml}$, [monomer]/[initiator] $=20$ (runs 2 and 3); monomer $0.5 \mathrm{~g}$, toluene $8 \mathrm{ml}$, [monomer]/[initiator] $=50$ (runs 4 and 5). ${ }^{\mathrm{b}} \mathrm{MeOH}$-insoluble part (runs 1-3); hexane-insoluble part (runs 4 and 5). ${ }^{\mathrm{c}}$ Determined by GPC analysis of PMMA derived from the original polymer. ${ }^{\mathrm{d}}$ Determined by ${ }^{1} \mathrm{H}$ NMR analysis of PMMA derived from the original polymer. ${ }^{\mathrm{e}}$ Measured in $\mathrm{CHCl}_{3}-2,2,2$-trifluoroethanol $(9: 1, \mathrm{v} / \mathrm{v})$ immediately after being dissolved [conc. $1.0 \mathrm{~g} \mathrm{dl}{ }^{-1}$, path length $0.5 \mathrm{dm}]$. ${ }^{\mathrm{f}} \alpha, \alpha^{\prime}-$ Azobis(isobutyronitrile). 

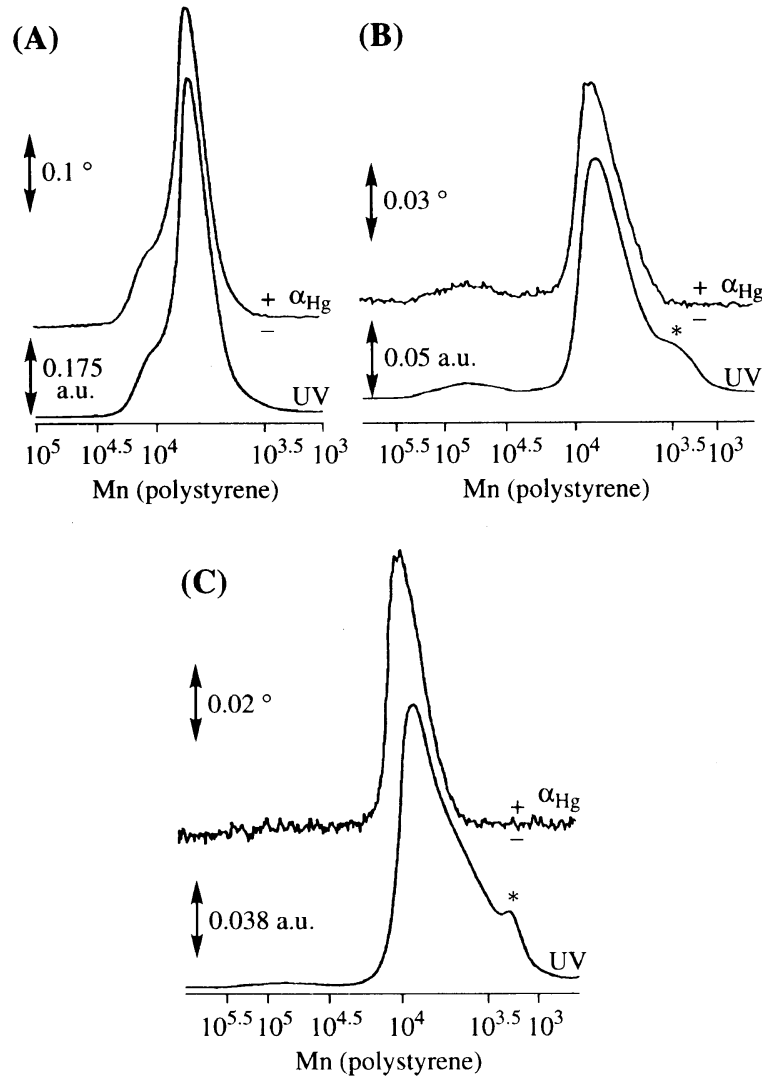

Figure 1. GPC curves of methanol insoluble poly(3PyDBSMA)s prepared with PMP (A), DDB (B), and Sp (C) (runs 1, 2, and 3 in Table II, respectively). For each of (A)-(C), the top curve shows the response of the polarimetric $\left(\alpha_{\mathrm{Hg}}\right)$ detector and the bottom one, that of the UV $(254 \mathrm{~nm})$ detector. Asterisked peaks are based on oligomers.

pyridyl group and Li cation between 2PyDBSMA and 3PyDBSMA.

Chiral structures of the poly(3PyDBSMA) were further investigated by means of GPC with simultaneous $\mathrm{UV}_{254}$ and polarimetric detections (Figure 1). For the polymers prepared with PMP and DDB, the chromatograms by polarimeter well correspond to the UV chromatograms except that the DDB polymer contains a small amount of oligomers showing low optical activity (asterisked shoulder peak in (B)), indicating that the PMP and DDB polymers have uniform chiral (single-handed helical) structure regardless of molecular weight. The peak in the molecular weight range $10^{4.5}-10^{5.5}$ for the DDB polymer may be based on aggregates. The $\mathrm{Sp}$ polymer which also contained oligomeric fractions (asterisked peak), however, showed an obvious discrepancy of the polarimeter and UV chromatograms in the range of molecular weight $10^{3.5}-10^{4}$; higher molecular weight-fractions exhibit stronger response in polarimetric detection. This may mean that helix-sense selectivity increases as a growing chain becomes longer.

3PyDBSMA also gave highly isotactic polymer even by free-radical polymerization at $40^{\circ} \mathrm{C}$ and at $60^{\circ} \mathrm{C}$ similarly to PDBSMA ${ }^{7}$ and 2PyDBSMA. ${ }^{13}$ The isotactic specificity in the polymerization of these three monomers is higher than other bulky triarylmethyl methacrylates including TrMA, D2PyMA, and D3PyMA.

\section{Stability of Helical Conformation}

Several optically active polymethacrylates having 638

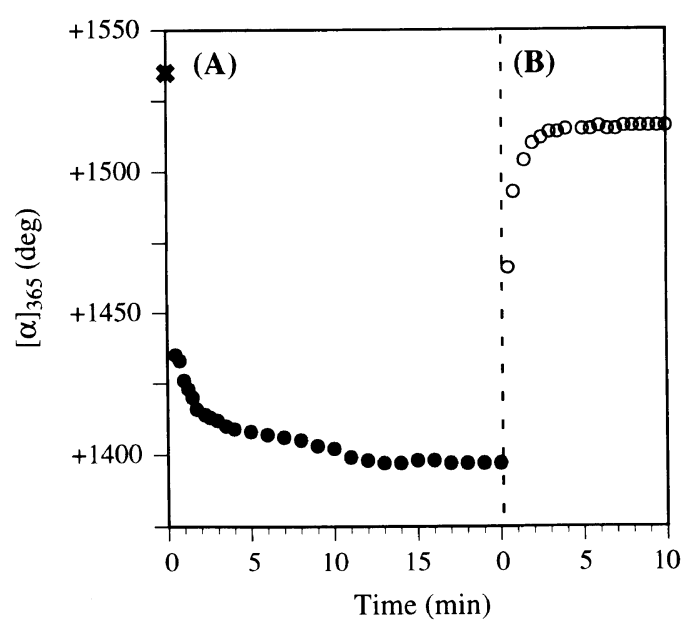

Figure 2. Change in optical activity of poly(3PyDBSMA) (run 1 in Table II) in chloroform at $60^{\circ} \mathrm{C}(\mathrm{A})$ and $25^{\circ} \mathrm{C}(\mathrm{B}){ }^{15} \times$ indicates $[\alpha]_{365}^{25}$ before the heat treatment at $60^{\circ} \mathrm{C}$ in (A).

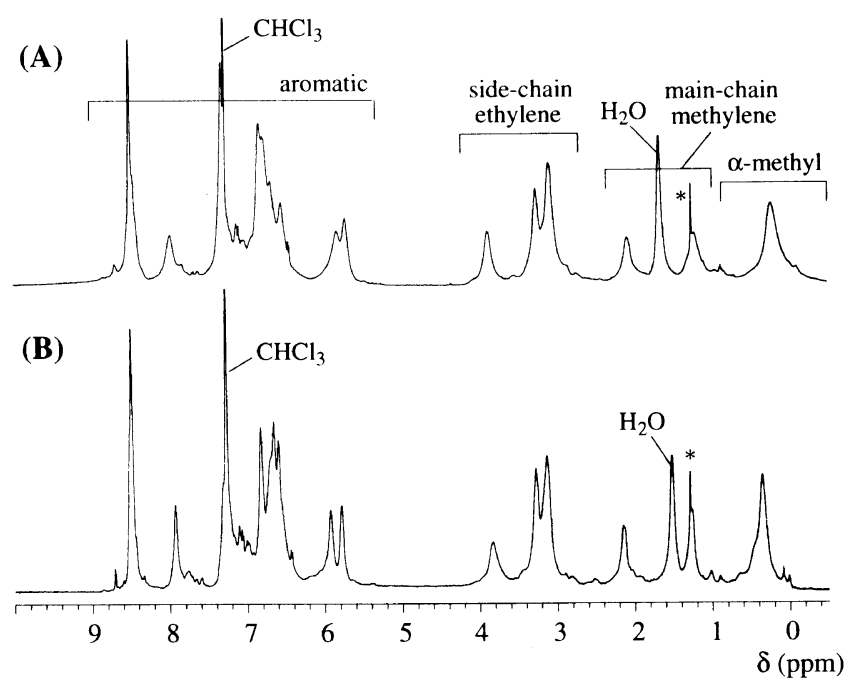

Figure 3. ${ }^{1} \mathrm{H}$ NMR spectra of poly(3PyDBSMA) (run 1 in Table II) in chloroform- $d$ at $25^{\circ} \mathrm{C}(\mathrm{A})$ and $60^{\circ} \mathrm{C}(\mathrm{B})$. Asterisked peaks are based on impurities.

helical conformation including poly(D2PyMA) ${ }^{14}$ and poly(D3PyMA $)^{11}$ are known to undergo helix-helix transition in solution. Since the transition may cause racemization of single-handed helix leading to a loss of optical activity as observed for poly(D2PyMA)s and can reduce chiral recognition ability, conformational stability is an important feature required for a helical polymer as a practical material.

In this context, stability of the poly(3PyDBSMA) was tested by monitoring mutarotation in chloroform at room temperature $\left(\mathrm{ca} .25^{\circ} \mathrm{C}\right)$ and at $60^{\circ} \mathrm{C} .{ }^{15}$ Figure 2 shows the mutarotation of the polymer obtained with PMPDPEDA-Li (run 3 in Table II). The polymer did not show any significant change in optical activity on standing a chloroform sample solution at room temperature but exhibited a decrease in optical rotation which took ca. 10 min to reach a constant value $\left([\alpha]_{365}+1397^{\circ}\right)$ which corresponds to $c a .91 \%$ of the original magnitude of optical activity $\left([\alpha]_{365}+1535^{\circ}\right.$ ) (Figure 2(A)). The reverse change, which was faster compared to the change at $60^{\circ} \mathrm{C}$, was observed on cooling the sample down to $25^{\circ} \mathrm{C}$ and the optical activity recovered to $[\alpha]_{365}$ 
Asymmetric Polymerization of 3PyDBSMA

Table III. Chiral absorption on helical polymethacrylates ${ }^{a}$

\begin{tabular}{|c|c|c|c|c|c|c|}
\hline \multirow{2}{*}{ Run } & \multirow{2}{*}{$\begin{array}{l}\text { Racemic } \\
\text { compound }\end{array}$} & \multirow{2}{*}{ Polymer } & \multirow{2}{*}{$\frac{\text { Adsorped sample }}{\%}$} & \multirow{2}{*}{$\frac{\text { e.e. in solution }}{\%^{\mathrm{b}}}$} & \multicolumn{2}{|c|}{ Separation factor ${ }^{\mathrm{c}}$} \\
\hline & & & & & $\alpha_{1}$ & $\alpha_{2}$ \\
\hline $2^{d}$ & & $(+)-$ Poly $(\text { PDBSMA })^{f}$ & 81 & $(+) 3.5$ & 1.08 & 1.08 \\
\hline 3 & & $(+)$-Poly $(2 \text { PyDBSMA })^{g}$ & 66 & $(+) 2.9$ & 1.09 & 1.06 \\
\hline 4 & & (+)-Poly(3PyDBSMA) & 64 & $(+) 6.6$ & 1.23 & 1.14 \\
\hline $5^{\mathrm{d}}$ & & $(+)-\operatorname{Poly}(\operatorname{TrMA})^{\mathrm{e}}$ & 50 & $(+) 10$ & 1.49 & 1.22 \\
\hline $6^{\mathrm{d}}$ & & $(+)$-Poly $(\text { PDBSMA })^{\mathrm{f}}$ & 78 & $(+) 1.8$ & 1.05 & 1.05 \\
\hline 7 & & $(+)$-Poly $(2 \text { PyDBSMA })^{g}$ & 68 & $(+) 6.0$ & 1.19 & 1.13 \\
\hline 8 & & $(+)$-Poly(3PyDBSMA) & 66 & $(+) 4.2$ & 1.14 & 1.09 \\
\hline
\end{tabular}

${ }^{a}$ At room temperature $\left(c a .25^{\circ} \mathrm{C}\right)$. See ExPERIMENTAL for detailed conditions. ${ }^{\mathrm{b}}$ Determined by HPLC analysis of the supernatant solution. ${ }^{\mathrm{c}}$ See EXPERIMENTAL for calculation methods. ${ }^{\mathrm{d}}$ Crude data were cited from ref 16 but the separation factors were calculated in this work. ${ }^{\mathrm{e}} \mathrm{DP}=60 . M_{w} / M_{n}=1.31(\operatorname{ref} 2) .{ }^{\mathrm{f}} \mathrm{DP}=39 . M_{w} / M_{n}=1.16(\operatorname{ref} 8) .{ }^{\mathrm{g}} \mathrm{DP}=51 . M_{w} / M_{n}=1.05(\operatorname{ref} 8)$.

ca. $+1515^{\circ}, c a .99 \%$ of the magnitude of original optical activity. This process could be reproduced using the same sample several times. The mutarotation appears to be based on some conformational change of the polymer, since no decomposition or configurational change in polymer structure through the thermal treatment was suggested by IR and ${ }^{1} \mathrm{H}$ NMR analysis. Based on the fact that the mutarotation was faster than those reported for poly(D2PyMA) ${ }^{14}$ and poly(D3PyMA) ${ }^{11}$ with similar DPs which undergo helix-helix transition and it was nearly completely reversible, the mutarotation may be ascribed more reasonably to some reversible conformational transition of side groups of polymer chain rather than to a helix-helix transition of the main chain. Therefore, it may be concluded that the single-handed helical conformation of the poly(3PyDBSMA) is more stable than that of the other polymethacrylates.

${ }^{1} \mathrm{H} \mathrm{NMR}$ analysis at $25^{\circ} \mathrm{C}$ and $60^{\circ} \mathrm{C}$ was performed to obtain information on structural transition accompanying the mutarotation (Figure 3 ). The spectra taken at the two temperatures showed obvious differences of spectral pattern in the aromatic region ( $c a$. 5.5-8.5 ppm) that can not be ascribed to general temperature effects on peak shape. However, in contrast, difference was only little in the region of $\alpha$-methyl, main-chain methylene, and side-chain ethylene signals ( $c a .-0.1-4$ ppm). This supports the assumption of the conformational transition in the side group which could modify the arrangement and overlapping of aromatic groups resulting in the spectral change in the aromatic region. The peak position of the $\alpha$-methyl signal $(-0.1-0.5$ ppm) which exhibited only slight down field shift on heating to $60^{\circ} \mathrm{C}$ may exclude the option of helix-random coil transition. A random-coil polymer would show its $\alpha$-methyl signals within the range of $c a .0 .5-1.5 \mathrm{ppm}$ as typically seen in the spectrum of PMMA.

\section{Chiral Recognition Using Optically Active Poly(D3Py- $M A$ )}

Chiral recognition ability of the poly(3PyDBSMA) obtained with PMP-DPEDA-Li was investigated by a chiral adsorption method and compared with that of single-handed helical poly(TrMA), poly(PDBSMA), ${ }^{16}$ and poly(2PyDBSMA) (Table III). trans-Stilbene oxide and Tröger's base were employed as racemates in this work. The poly(3PyDBSMA) was able to resolve the two racemic compounds. The separation factor for the poly(3PyDBSMA) was similar to those for the other polymers bearing 1-aryldienzosuberyl side groups and much lower than those for the poly(TrMA). The antipode preferentially adsorbed on to the poly(PDBSMA), poly(2PyDBSMA), and poly(3PyDBSMA) had the same handedness (chirality), suggesting that the mechanisms of chiral adsorption for the poly(PDBSMA), the poly(2PyDBSMA), and the poly(D3PyMA) are similar.

\section{Conclusions}

3PyDBSMA was synthesized and found more durable than PDBSMA but less durable compared to 2PyDBSMA and D3PyMA against methanolysis. 3PyDBSMA gave nearly perfectly isotactic polymers under asymmetric anionic and free-radical polymerization conditions. The polymer obtained by asymmetric anionic polymerization possessed single-handed helical conformation and exhibited chiral recognition ability toward trans-stilbene oxide and Tröger's base. The helical conformation was stable in a chloroform solution at $60^{\circ} \mathrm{C}$ and only exhibited reversible mutarotation which is probably due to some side-chain conformational transition.

\section{REFERENCES AND NOTES}

1. Y. Okamoto, K. Suzuki, K. Ohta, K. Hatada, and H. Yuki, J. Am. Chem. Soc., 101, 4763 (1979).

2. T. Nakano, Y. Okamoto, and K. Hatada, J. Am. Chem. Soc., 114, 1318 (1992).

3. Y. Okamoto, H. Mohri, and K. Hatada, Chem. Lett., 1988, 1879.

4. Y. Okamoto, H. Mohri, T. Nakano, and K. Hatada, Chirality, 3, 277 (1991).

5. (a) Y. Okamoto and T. Nakano, Chem. Rev., 94, 349 (1994). (b) T. Nakano and Y. Okamoto, in "Catalysis in Precision Polymerization," S. Kobayashi, Ed., Wiley, New York, N.Y., 1997, pp 293-309.

6. (a) Y. Okamoto, CHEMTECH, 1987, 144. (b) Y. Okamoto and K. Hatada, J. Liq. Chromatogr., 9, 369 (1986).

7. T. Nakano, M. Mori, and Y. Okamoto, Macromolecules, 26, 867 (1993).

8. T. Nakano, A. Matsuda, M. Mori, and Y. Okamoto, Polym. J., 28, 330 (1996).

9. T. Nakano, Y. Shikisai, and Y. Okamoto, Polym. J., 28, 51 (1996).

10. T. Nakano, A. Matsuda, and Y. Okamoto, Polym. J., 28, 556 (1996).

11. T. Nakano, K. Taniguchi, and Y. Okamoto, Polym. J., 29, 540 (1997).

12. Y. Okamoto, H. Mohri, and K. Hatada, Polym. J., 21, 439 (1989). 
T. NaKano, Y. SATOH, and Y. OKamoto

13. T. Nakano, A. Matsuda, and Y. Okamoto, manuscript in preparation.

14. Y. Okamoto, H. Mohri, T. Nakano, and K. Hatada, J. Am. Chem. Soc., 111, 5952 (1989).

15. Sample concentration was originally determined based on the sample volume at room temp $25^{\circ} \mathrm{C}$ but the concentration at $60^{\circ} \mathrm{C}$ has been corrected using a calculated volume increment of chloroform $(4.8 \%)$ with respect to the volume at $25^{\circ} \mathrm{C}$. For the method of calculation, see: "Landolt Börnstein Zahlenwerte und Funktionen aus Physik, Chemie, Astronomie, Geophysik und Technik," 6 Aufl., II Band, 1 Teil, Springer Verlag, 1971, S. $378-718$.

16. Y. Okamoto, T. Nakano, Y. Shikisai, and M. Mori, Makromol. Chem. Symp., 89, 479 (1995). 